\title{
A FEB CHEGA À LINHA GÓTICA.
}

\author{
DEMOCRITO ARRUDA \\ Capitão $\mathrm{R} / 2$ do Exército e Licenciado em Ciências \\ Sociais pela Faculdade de Filosofia, Letras e Ciências \\ Humanas da Universidade de São Paulo.
}

A 16 de julho de 1944, aportava à uma Nápoles semi-destruida o 10 escalão da FEB, Força Expedicionária Brasileira.

Seu efetivo era modesto, mas representativo: um regimento de infantaria, o velho $6^{\circ}$ de Caçapava, São Paulo, um grupo de artilharia, uma companhia de engenharia, elementos diversos de intendência, saude, transmissões, constituindo um Grupamento de Combate de 5:100 homens.

Sua composição, um mural do povo brasileiro, gente de todas as regiões, condições sociais e origens. Velhos troncos lusitanos ombreando descendentes de japoneses e italianos, mestiços, afro-índios ao lado de teutos, poloneses e quantos mais enriquecem a etnia de um povo multi-racial.

Estariam preparados? Não, de todo. Sua organização estava cheia de furos. Seleção física defeituosa. Treinamento incompleto. Escassez de especialistas. Quadros sem experiência de combate. Equipamento e armamento a receber, desconhecidos. Fardamento inadequado. Pouca confiança nos chefes. Em compensação, superando todas as fraquezas, uma insuspeitada disposição de combate que se revelaria na hora oportuna.

Ao pisar território italiano, começava psicologicamente a sua inoculação da batalha.

A visão da baia napolitana coalhada de centenas de poderosas naves de guerra, o horizonte encoberto de balões cativos, os destroços de inúmeras embarcações afundadas no porto, quarteirões inteiros desmoronados, um bombardeio noturno da aviação alemã à base naval e a violenta reação da artilharia anti-aérea, seriam os primeiros dados dessa experiência memoravel. 
Problemas imediatos do Grupamento: receber o material de guerra, completar a formação dos especialistas requeridos, instruir a tropa e aguardar a sua primeira missão de combate.

Dois meses exatos de estada e alguns dias de treinamento decorreriam até à sua entrada em combate. De início, a tropa acampou na cratera de um vulcão extinto nos arredores de Nápoles, o Astroni, em condições precárias de instalação e embaraçosa inatividade. Em princípios de agosto, deslocou-se para Tarquínia onde recebeu armamento, equipamento e viaturas e foi incorporada, oficialmente, ao 4 9 Corpo do 5 ? Exército americano. Em princípios de setembro, abarracava em Vada, ao sul de Livorno, onde se ouvia o troar da artilharia no campo da batalha.

\section{Uima Estratégia pouco Napoleônica.}

A chegada do 10 escalão, as operações na Itália situavam-se nas alturas de Arezzo e lutava-se, ainda, por Livorno e Ancona. Sob o comando de um habil general, Kesselring, os alemães retiravam-se, lenta e metodicamente, para o rio Arno, última linha retardadora antes da Linha Gótica. Usufruiam a vantagem inesperada que lhes concedera o alto comando aliado, em Washington, com a consumação de um clamoroso erro estrategico, o maior da campanha italiana.

De acordo com uma decisão tomada na conferência anglo-americana de Quebec, agosto de 1943, as tropas aliadas, uma vez transposto o Tibre, deveriam restringir as suas atividades na Itália e ceder parte dos seus efetivos à uma nova operação de desembarque no sul da França, conjugada com a invasão da Normandia. Estimavam, então, os planejadores americanos que essa linha estratégica traria resultados decisivos. Levada ao conhecimento de Stalin em Teheran, este aplaudiu-a e passou a exigir o seu cumprimento. De sócio prestimoso e cúmplice de Hitler nos idos de 1939-41, Stalin alçara-se a árbitro da estratégia aliada. Para os americanos, calouros da Realpolitik, a decisão tornara-se um compromisso a ser honrado.

Mas, quando os aliados chegaram ao Tibre, a 4 de junho de 1944 , a situação estratégica exigia uma reavaliação. Os exércitos aliados ostentavam uma nítida superioridade em homens, equipamento e moral, enquanto a posição dos exércitos alemães, segundo Kesselring, era catastrófica (1). Expugnados nas posições fortificadas de

(1). - Kesselring (Marechal), Soldat jusqu'au dernier jour. Charles Lavauzelle \& Cie, Paris, 1956. 
Cassino, cinco divisões de infantaria destroçadas, suas grandes unidades blindadas severamente desgastadas, os alemães estavam em raza campanha, em plena retirada, à mercê da aviação anglo-americana . Pareciam reunidas as condições ideais de uma batalha de aniquilamento e tudo indicava que o exército teuto poderia ser destruido ao sul dos Apeninos.

Com a possivel destruição dos exércitos inimigos, esboçar-se-ia uma grandiosa manobra estratégica, acalentada por Churchill: conquista imediata do vale do Pó, com seus vastos recursos humanos e industriais; avanço relâmpago sobre a Europa Central, através da Liubliana, tendo Viena como objetivo; provavel encurtamento do final da guerra e uma geografia política diferente nos Balkans do após-guerra.

A vitória, entretanto, não seria completada. Um exército vitorioso, perseguindo um inimigo batido e desequilibrado, seria paralisado, pois os chefes do estado-maior americano impuzeram a execução literal das decisões tomadas um ano antes. As operações foram desaceleradas, oito divisões aliadas, das mais experientes, retiradas do front e concentradas, inativas, em Nápoles, à espera do desembarque no sul da França. Este ocorreu a 15 de agosto de 1944, com minguados resultados encontrando já os alemães em retirada voluntária.

A estimativa estratégica americana, imposta aos britânicos, falhara por completo: nem desembarque simultâneo na França, nem aproveitamento do êxito na Itália. Falhara por amarrar-se demasiado a um plano estabelecido um ano antes, longe das contingências do campo de batalha e, principalmente, por desvincular-se dos objetivos políticos do após-guerra.

A campanha aliada na Itália prosseguiria, mas em ritmo lento, sem capacidade para um golpe decisivo. $O$ afortunado Kesselring, salvo pela miopia estratégica e burocrática de Washington, pode organizar a sua retirada e restabelecer a linha alemã como um todo coerente. Retirava-se lenta e metodicamente, linha após linha, com o objetivo de ganhar tempo enquanto trabalhava na Linha Gótica, onde poderia aguentar o inverno de 1944-45.

\section{A Linha Gótica.}

Chamou-se Linha Gótica ao sistema de defesa organisado pelos alemães na dorsal dos Apeninos, coluna vertebral da península italiana. Começava no litoral oeste em Massa e sempre acompanhando a linha de cristas terminava em Pesaro, no Adriático. 
Batizada com esse nome pelos alemães, tornou-se conhecida dos aliados graças a um mapa capturado num quartel-general germânico. Mais tarde, rebatizaram-na de Linha Verde mas, do lado aliado, a magia do primeira nome prevaleceu e ficou sempre como Linha Gótica.

Fora cogitada, pela primeira vez, quando Mussolini foi preso e esboroou-se o regime fascista. Na confusão posterior, Hitler pretendeu abandonar todo o sul da Itália e concentrar a força teuta nos Apeninos. Kesselring convenceu $\cdot \mathrm{o}$ a lutar na bota italiana, mas procedera-se ao reconhecimento da Linha e alguns trabalhos foram iniciados ao longo dos seus 280 quilômetros.

Enquanto se sucediam os combates em Cassino, ativou-se a sua construção. A organisação Todt, especiazada em trabalhos de defesa, veio colaborar e milhares de italianos, recrutados à força, foram empregados nesse programa de fortificação. A cadeia dos Apeninos, obstáculo imponente para uma força atacante, somou-se toda uma gama de recursos à disposição do engenho militar. Minas e arame farpado, abrigos de concreto, fossos anti-carro, espaldões para metralhadoras, embasamentos para artilharia, campos de tiros, estradas laterais, foram preparadas com minúcia germânica. A linha era especialmente trabalhada nos setores costeiros e nos colos das estradas que cortam o maciço em direção ao vale do Pó, eixos naturais do avanço aliado.

Em princípios de setembro de 1944, o programa não estava ainda perfeito, mas a posição estava em condições de defender-se e atingira uma profundidade consideravel. $\mathrm{O}$ trabalho realizado era satisfatório, segundo Kesselring.

Justo em tempo, porque o ataque aliado, projetado em dois lances, já se desencadeava.

No primeiro, o $8^{\circ}$ exército britânico transportava em segredo, em fins de agosto, o seu centro de gravidade do meio da península, em torno de Florença, para o Adriático e surpreendia inteiramente os alemães; quebrando a Linha Gótica naquela zona e arremetia em direção de Rimini. Para enfrentar a ameaça, Kesselring abandona o Arno, recua as divisões restantes para a Linha Gótica e transfere suas reservas para a frente britânica.

Era a oportunidade aguardada pelo $5{ }^{\circ}$ exército americano para o segundo lance. Atravessa o Arno e procura contacto com as defesas avançadas da Linha. A 10 de setembro, está pronto para atacar; a 13 , com seu $2^{\circ}$ Corpo, começa a sua ofensiva principal no eixo da estrada Florença-Bolonha, buscando a rotura no passo de Il Giogo. A batalha, de uma intensidade tremenda, alcançaria a ruptura da 
Linha Gótica, naquele setor, a 21 de setembro mas iria prolongar-se até fins de outubro na tentativa gorada de chegar à Bolonha.

Enquanto se desenrolava esse ataque. tambem o 49 Corpo passava à ofensiva, entre Florença e o Mar Tirreno. Incorporados a este último, os brasileiros iriam participar, em setor próprio, das emoções dessa arrancada contra a Linha Gótica.

\section{Primeira Missão Brasileira.}

Na noite de 12 de setembro, o Destacamento brasileiro recebia do 4 ? Corpo a sua primeira ordem de operações. Com a organizaçăo de um Combat-Team, devia substituir, na noite de 15 de setembro, tropas americanas em posição na região de Vecchiano e, em seguida, atuar ofensivamente em direção geral do norte.

A notícia ecoou rápida no acampamento de Vada. A modorra burocrática, normal nos campos militares, sucedeu uma febril atividade e um novo estado de espírito tornou-se perceptivel entre os combatentes. Desaparecia o receio de que a guerra terminasse sem que a FEB tivesse combatido. Ninguem aceitava o papel de tropa auxiliar ou de tropa de ocupação. Um povo orgulhoso exigia o seu lugar de combatente. $O$ desejo de ação era geral, parecia despertado o apetite da luta. Se a guerra terminasse de repente, naquele momento, seria uma das coisas mais tristes para os febianos. Todo esforço anterior, meses de sacrifícios, suor, lágrimas, adquiriam sentido. Essa atmosfera não escapou à perspicacia do General Mark Clark, comandante do $5^{\text {O}}$ exército americano:

"os brasileiros, de modo geral, estavam ansiosos por entrarem em ação. De fato, era tal a pressa deles que, provavelmente, não completaram o treinamento de que precisavam após a chegada à Itália" (2).

Na noite de 15 para 16 de setembro, os brasileiros ocupavam, pontualmente, posições de combate na região de Vecchiano, no encontro aprazado com a História.

Aquela noite talvez tenha sido de rotina ao longo das centenas de quilômetros de linha na península italiana; talvez uma noite a mais para os milhares de calejados e enfarados veteranos. Mas, para os

(2). - Clark (General Mark W.), Risco Calculado. Biblioteca do Exército Editora, 1970. 
recem-chegados, os mais novos combatentes do front italiano, foi uma noite memoravel de intensas emoçōes. Uma página nova na vida de cada um e na vida de um povo. Malraux, combatente fogoso de muitas lutas, diz com razão que

\footnotetext{
"nenhuma palavra descreve o sentimento de marchar ao encontro do inimigo e, no entanto, ele é tão específico, tão forte quanto o desejo sexual ou a angústia".
}

A região atribuida à $\mathrm{FEB}$, nessa primeira fase, situa-se ao norte de Pisa e oeste de Lucca, cidades ligadas sentimentalmente ao Brasil por numerosos imigrantes saidos dali. No quadro das operações, colocava-se no flanco, sempre vulneravel, do $5^{\circ}$ exército e a poucos quilômetros da sua estrada principal de abastecimentos.

O terreno é acidentado e progressivamente montanhoso; localizam-se ali os primeiros contrafortes dos Alpes Apuanos, Apeninos ocidentais. Ultrapassada a planície pisana, o modelado apresenta uma série de pequenos morros de 200 a 300 metros de altura; depois, começa a elevar-se, gradativamente, até alcançar picos alcantilados de 1.000 a 1.800 metros de altitude, numa profundidade média de quinze quilômetros, em zona de dificil acesso. Na parte baixa, os vales são cortados por boas estradas e densamente povoados, com inúmeras cidades e aldeias. Os campos bem cultivados. Nas cotas próximas dos mil metros, terminam as estradas, surgem as picadas mulateiras, rarefece a vida humana. E o domínio das rochas, dos grotões, dos picos inacessiveis de extraordinária beleza.

Nesse relevo agressivo, os brasileiros do 19 escalão iriam fazer o seu noviciado de guerra.

O soldado alemão exercia uma ascendência moral muito forte . Era um veterano de muitas campanhas e muitas vitórias. Seus feitos espetaculares fascinavam profissionalmente. Disciplinado, duro, audacioso e enquadrado por uma oficialidade competente, era uma máquina perfeita de fazer guerra. Era respeitado e temido.

As primeiras informações sobre o inimigo à frente, foram imprecisas. A tropa americana substituida, um antigo regimento de artilharia anti-aérea transformado em infantaria. era de fraca combatividade e não mantinha contacto cerrado com os alemães. Os efetivos teutos eram desconhecidos, caiam tiros sobre a região de Pisa e vizinhanças e havia uma terra de ninguem, de quatro a seis quilômetros, percorrida diariamente por patrulhas inimigas. As posições de resistência estariam nos Montes Prano, Valimono, Acuto, Conservo. Mais tarde, pe- 


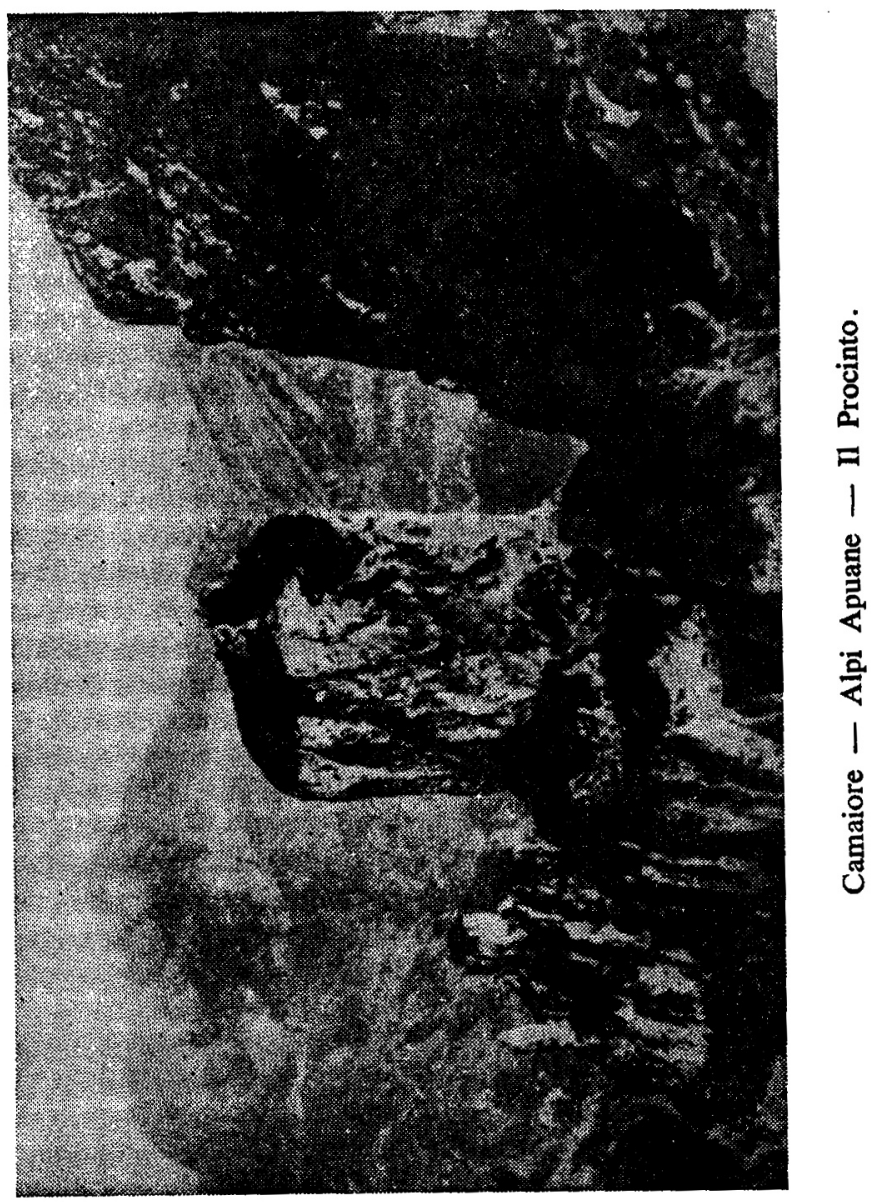


los primeiros prisioneiros capturados, soube-se que estava ali o $25^{\circ}$ regimento da 42 a divisão de infantaria alemã.

\section{Desenvolvimento da Missão.}

Na própria noite da substituição, diversas patrulhas de infantaria foram lançadas à frente, sem contacto com o inimigo .

$\mathrm{Na}$ tarde de 16, o Destacamento, em característica marcha para o combate, inicia a sua progressão. Apoiada por um grupo de artilí.aria, uma companhia de engenharia, um pelotão de carros e seus próprios elementos, a infantaria do velho $6^{\circ}$ de Caçapava lançou-se decididamente para o norte, numa frente inicial de oito quilômetros. Tinha dois batalhões em primeiro escalão e, estes, duas companhias justapostas. O avanço processou-se sob forte bombardeio de artilharia e morteiros. Era o batismo de fogo!

Rapidez e agressividade não lhe faltaram na busca do contacto. No fim da primeira jornada, uma penetração média de cinco quilômetros e a primeira transversal Lucca-Viareggio, entre Massarosa e ponte S. Pietro, no rio Sérchio, estava em seu poder, envolvendo uma série de localidades sob os aplausos delirantes da população italiana que os recebia, como libertadores, com pão, vinho e beijos, mesmo sob os tiros da artilharia inimiga.

A 17, prossegue o avanço para o norte, entre cotas de 400 a 600 metros, entre Monte Ghilardona a oeste, Piazzano, Monte Castelacio, a cavaleiro da penetrante Lucca-Camaiore. O inimigo manifesta-se por tiros de artilharia e morteiros sobre as unidades de vanguarda, alem das demolições. De um modo geral, retirava-se sob pressão, fugindo ao contacto.

A 18, a topografia mais amena à esquerda do dispositivo, facilita ao 1 \% batalhão uma investida em flecha de oito quilômetros no sentido noroeste, enquanto nó centro e à direita a marcha é mais lenta e mais penosa. A última transversal antes do paredão dos Apuanos é cortada na aldeia de La Rena e por ela elementos combinados infiltram-se audaciosamente até à cidade de Camaiore, nó de comunicações, que foi ocupada sob forte bombardeio de artilharia e morteiros. Camaiore acha-se no fundo de uma bacia dominada pelo Monte Prano, bastião principal da Linha Gótica nessa zona.

A 19, enquanto o primeiro batalhão consolidava, sob pesados bombardeios, suas posições em Camaiore, os batalhões restantes, em terreno mais agreste, aproximam-se e ultrapassam, em toda a sua ex- 
tensão, a estrada Lucca-Camaiore, procurando alinhar o dispositivo, estirado à esquerda. Os bombardeios da artilharia alemã cobrem as colunas avançadas enquanto destruições de vulto são executadas em locais apropriados. A engenharia tinha de que se ocupar: só nessa estrada, seis pontes destruidas, alem dos campos de minas e das demolições. Capturados os primeiros prisioneiros.

Nesse momento, estava estabelecido o contacto com os postos avançados da Linha Gótica, instalados, de oeste para leste, nos Montes Prano, Valimono, Acuto e Conservo. A frente de luta estendia-se por 13 quilômetros dentro da cordilheira. As cristas eram pontos de apôio ocupados por sub-unidades alemãs, reforçadas por ações de morteiros e artilharia.

Para os brasileiros, as montanhas tornavam-se cada dia mais altas, mais abruptas; as ravinas mais fundas e estranguladas; as jornadas mais penosas. As estradas tinham terminado, os veículos ficado atraz, nem mesmo os jeeps conseguiam avançar. Como se faltasse alguma coisa, começaram as chuvas do outono, chuvas pesadas, copiosas, para tormento dos homens. Multiplicaram-se as dificuldades. $\mathrm{O}$ abastecimento tornou-se problema quase insoluvel. Para remediar, uma centena de muares com condutores alpinos italianos foi incluida na tropa brasileira.

Sem treinamento prévio, sem material especializado, os brasileiros faziam, de saida, uma guerra de montanha. Tropas destreinadas em combates de montanha, dizem os especialistas, sofrem um bloqueio mental. Von Senger, general e um dos comandantes alemães na Itália, acrescenta que

"para os soldados acostumados ao terreno plano, a montanha intensifica os seus temores e desmoraliza-os, enquanto para os montanheses é uma proteção e tambem uma arma" (3).

Delimitada a Linha, restava ocupar os seus bastiões, quatro montes dominadores, defendidos por fortes organizações de terreno, campos de minas, redes de arame, armas automáticas e morteiros, observatórios perfeitos, enfiando pela vista e pelo fogo varios quilômetros da retaguarda brasileira. Monte Prano, com os seus 1.220 metros de altitude, era espetacular.

A idéia inicial do comando do Destacamento foi conquistar primeiro Monte Prano, depois o restante da Linha. O plano se realizaria através de um desbordamento pelo oeste que foi iniciado com pe-

(3). - Burton (Hal), The Ski Troops. A History of the 10th Mountain Division. Simon and Schuster. New Yok, 1971. 
queno avanço sobre Casoli e dai atingiu Pomezzana, por ínvias veredas, em plena cordilheira, acima dos mil metros. A distância Casoli-Pomezzana é de três quilômetros na carta; seu percurso exigiu seis horas de marcha, marcha lenta, exaustiva, homem a homem, à beira dos precipícios.

Durante seis dias prosseguiram as tentativas de envolvimento pelo oeste, mas sem resultados. A resistência do inimigo bloqueiando as poucas vias de acesso e as dificuldades insuperáveis da montanha, aumentadas pelas chuvas pesadas, anularam a manobra. Ficou famosa nesses dias uma patrulha comandada pelo Tenente Cabral que aproveitando habilmente as dobras do terreno e a neblina existente, conseguiu chegar à cota 1.096 do Monte Prano, onde surpreendeu os alemães em plena folga, causou-lhes inúmeras baixas e retirou-se sem perdas, apesar da violenta reação que se seguiu.

Frustada a manobra daquele lado, retomou-se, a 25, a operação pelo leste, por insistência do Coronel Segadas, habil comandante do 69 R. I. Percebera este que os reabastecimentos do Monte Prano eram feitos do leste, através de um caminho vindo de Convale, à direita do nosso dispositivo. Era necessário cortar esse caminho, atacando pela direita brasileira, a fim de isolar Monte Prano.

$\mathrm{O}$ ataque, planejado e orientado pelo regimento, desenrolou-se conforme fora previsto. Os segundo e terceiro batalhões, com adequado apôio do grupo de artilharia, progrediram firmes para seus ob;etivos, sob cerrado fogo de artilharia, morteiros e armas automáticas inimigas. A $4^{\text {a }}$ companhia ocupou Monte Acuto, a $5^{\mathrm{a}}$ entrou em Fiano, a $3^{a}$ galgou o Valimono, a $8^{\text {a }}$ escalou o 833 . Virtualmente cercados pelos dois lados, os alemães retiraram-se de Monte Prano na madrugada de 26.

Estava rompido o dispositivo alemão e as posições que balizavam a Linha Gótica, nessa região, estavam em mãos dos brasileiros. Os alemães retiraram-se para os elevados picos situados alguns quilômetros ao norte, onde permaneceriam até o último dia de guerra, e os brasileiros seriam deslocados, logo depois, para novo setor, no Vale do Sérchio, onde iriam tambem dar provas de um vigoroso espírito ofensivo.

Em dez dias, o Destacamento progredira 18 quilômetros dentro do dispositivo inimigo, numa frente inicial de 8 , alargada progressivamente para 13 quilômetros. Libertara dezenas de localidades e fixara 
o inimigo, retendo algumas das suas reservas. Expulsara-o, por fim, de suas posições fortemente organizadas em magníficos pontos estratégicos.

Prisioneiros alemães capturados nessa primeira fase: 45. Nossos, nenhum. Baixas adversárias, não controladas. Nossas baixas, 35, assim distribuidas: 5 mortos, 21 feridos, 9 acidentados.

Taticamente, foi uma guerra típica de infantaria. Em especial, das pequenas unidades, companhias e batalhões que, pelo movimento, pela infiltração e desbordamento, iam atingindo os seus objetivos. Cercadas ou ameaçadas de cerco, as sub-unidades inimigas batiam em retirada. Contou-se, é certo, com o apôio eficiente da artilharia para amaciar as posições visadas ou da engenharia para reorganizar as comunicações.

Mas o mérito maior foi da infantaria. Sem ela, o inimigo provavelmente não teria sido desalojado. Infantaria era o pracinha, simples, despretensioso, bravo. Tinha a mesma garra daqueles que lutaram nos charcos do Paraguai.

Para uma tropa neófita, sem treinamento algum de guerra de montanha e contra um veterano duro, como o soldado alemão, a sua conduta foi modelar.

DEMOCRITO CAVALCANTI DE ARRUDA. - Classe 1918. Natural de Bonito de Santa Fé (Paraiba).

Bacharel em Ciências Jurídicas pela Faculdade de Direito de Recife (1939) e Licenciado em Ciências Sociais pela Faculdade de Filosofia, Ciências e Letras da Universidade de São Paulo (1942).

Oficial da Reserva, CPOR da $7^{\text {a }}$ Região Militar (Recife). Turma de 1938. Convocado pelo Exército de 1942 a 1945.

Embarcou com o $6^{\circ}$ Regimento de Infantaria (Caçapava), como Tenente, voltando como Capitão. Ferido em Montese.

Medalhas: de Guerra, de Campanha, Cruz de Combate e Sangue do Brasil.

Coordenador e co-autor do livro, Depoimento de Oficiais da Reserva sobre a FEB. São Paulo. IPE. 1949 (19a ediçāo). 